\title{
Passive Keyless Entry Locking Door with ESP32
}

\author{
Arya Wibisono $^{1}$, M.B.Nugraha ${ }^{2}$, Michael Aldo Amosen ${ }^{3}$, Reza Afriani Maulana ${ }^{3}$ \\ 1, 2,3 Teknik Elektro, Universitas Multimedia Nusantara, Tangerang, Indonesia \\ alexwibisono18@gmail.com \\ mb.nugraha@umn.ac.id
}

Diterima 10 Mei 2020

Disetujui 19 Juni 2020

\begin{abstract}
In modern times, technology advancement become more sophisticated and advanced and accessible for everyone. This trend leads to people can buy dangerous and criminal related tools such as lockpick easily and also learn how to lockpick from the internet. Conventional key system has tendencies to be easily hacked lead to unauthorized access to our property. Passive keyless entry system already used in automotive industry, especially in high-end car. This research trying to recreate the keyless entry system for home using RFID.
\end{abstract}

Index Terms-ESP32, High Frequency RFID, Keyless Entry, Passive Keyless Entry, PKE, RFID

\section{PENDAhUluan}

Mengutip pada Statistik Kriminal 2019 pada badan pusat statistik (BPS) pada websitenya, angka tindak kejahatan dari tahun 2016 - 2018 terus menurun, tetapi walaupun angka tindak kejahatan menurun bukan berarti menjadi tidak waspada pada keamanan diri sendiri. Mengutip juga pada Statistik Kriminal 2019, jumlah desa/kelurahan yang melaporkan kejadian kriminalitas jenis pencurian terus meningkat pada 2011, 2014, dan 2018. Pada tahun 2011 terjadi $36.78 \%$ tindak pencurian, di tahun 2014 terjadi 41.05\% tindak pencurian dan di tahun 2018 terjadi $45.01 \%$ tindak pencurian. Dari data tersebut bisa terlihat bahwa tindak pencurian yang terjadi terus meningkat oleh karena itu, pada jaman canggih ini, kunci fisik yang dianggap kuno akan sering mengalami pembobolan karena lebih mudah untuk dilockpicking dengan lockpicking set yang sudah banyak dijual dimana - mana.

Maka dari itu, dalam penelitian ini mencoba mengubah kunci fisik menjadi kunci digital dengan sistem passive keyless entry (PKE). Teknologi PKE sudah banyak diterapkan pada otomotif modern saat ini untuk meningkatkan sistem keamanan dan kenyaman bagi pengguna mobil tersebut.[1]. Dengan menggunakan keyless entry, celah keamanan dalam bentuk lubang kunci berhasil diminimalisasi.

Berbeda dengan remote keyless entry (RKE) dimana pengguna harus menekan suatu tombol atau trigger lalu dari kunci tersebut akan mengeluarkan sinyal ID yang akan dibaca oleh antena receiver lalu melakukan aksi selanjutnya [2]. PKE hampir mirip dengan RKE tetapi antena di receiver akan selalu mencari sinyal ID dan ketika kunci terbaca oleh antena tersebut maka akan melakukan aksi selanjutnya dengan menerapkan sistem ini, maka tidak perlu ada menekan suatu tombol atau trigger untuk melakukan aksi lanjutan [1].

Sistem yang sudah diterapkan pada mobil saat sekarang ini akan dicoba pada percobaan kali ini dengan memasangkan sistem PKE pada suatu pintu rumah menggunakan ESP $32-30$ pin sebagai mikrokontrolernya dengan begitu sistem keamaan akan bertambah karena tidak menggunakan kunci fisik melainkan kunci digital yang bisa dibawa kemana mana. Selain menambahkan keamaan pada suatu rumah, sistem ini juga menambahkan kenyamanan karena pengguna hanya perlu mendekati pintu tersebut dan pintu akan otomatis membuka kunci dan tidak perlu memasukkan anak kunci.

\section{KAJIAN LITERATUR}

\section{A. Radio Frequency Identification}

Radio Frequency Identification (RFID) adalah sebuah alat identifikasi yang menggunakan gelombang radio untuk mengirimkan suatu sinyal. Ada 2 tipe RFID pada umumnya, RFID aktif dan RFID pasif. Penelitian ini hanya akan membahas mengenai sistem RFID pasif

Sistem RFID pasif (Passive RFID system) bekerja dengan cara RFID reader akan selalu memancarkan sinyal termodulasi lalu saat coil pada kartu atau tag RFID menerima sinyal tersebut, chip sirkuit yang berada di kartu RFID akan aktif dan mengeluarkan User Identification (UID) berupa kode hexadecimal yang panjangnya bergantung pada jenis RFID yang digunakan. UID akan diterima oleh reader saat melalui coil kartu mengirimkan sinyal hambur balik (backscattered) [2].

Ada beberapa tipe RFID yang beredar dipasar yang dibedakan dengan frekuensi yang digunakan oleh kartu tersebut [3]. Tipe yang pertama adalah Low-Frequency (LF) dimana rentang frekuensi yang 
digunakan adalah $125 \mathrm{kHz}$. dan $134.3 \mathrm{kHz}$ dan jarak baca pada kondisi ideal akan mencapai $30 \mathrm{~cm}$. Tipe yang kedua adalah High-Frequency (HF) dimana frekuensi yang digunakan adalah $13.56 \mathrm{MHz}$ dan jarak baca pada kondisi ideal akan mencapai 1.5 meter. Tipe yang ketiga adalah Ultra-High-Frequency (UHF) dimana rentang frekuensi yang digunakan adalah $860 \sim 960 \mathrm{MHz}$ dan jarak baca pada kondisi ideal 1 meter (untuk generasi lama), pada kartu generasi 2 jarak baca pada kondisi ideal bisa mencapai 16 meter.

\section{B. Passive Keyless Entry System}

Sebuah keyless Entry yang memanfaatkan passive tag dan sebuah antena dimana antena ini akan menghasilkan suatu sinyal dalam jarak tertentu dan ketika passive tag terdeteksi di dalam jarak itu, maka akan menghidupkan seluruh sistem untuk mengerjakan suatu aksi yang sudah dirancang.

PKE diterapkan untuk membuka atau menutup suatu pintu secara otomatis ketika passive tag terbaca. Data yang terdapat dalam passive tag akan dibandingkan dengan data yang terdapat dalam database dan ketika sudah nilai yang dikeluarkan adalah TRUE maka sistem akan berjalan dan membuka pintu tersebut. Sistem komparasi ini biasa disebut dengan back-end database [4].

Sistem PKE berbasis RFID sudah cukup banyak dijual di pasaran, namun sistem kerjanya masih serupa dengan RFID biasa dimana pengguna diharuskan untuk menempelkan kartu atau tag ke perangkat RFID reader. Sistem ini juga biasanya sudah dalam bentuk satu kesatuan dengan kunci pintu sehingga tidak dapat dipisahkan. Hal ini yang membedakan dengan sistem lainnya, dimana sistem ini berbentuk modular dan menggunakan konsep passive keyless entry dimana pengguna tidak perlu menempelkan kartu atau tag. Reader didesain untuk mengenali UID kartu atau tag dalam jarak tertentu.

\section{Metodologi Penelitian}

Dalam percobaan kali ini akan terbagi menjadi dua metode:

\section{Wiring \\ 2. Coding}

Alat - alat yang digunakan adalah:

1. 1 buah ESP32 - 30pin

2. 2 buah RFID tag $13,56 \mathrm{Mhz}$

3. 1 buah RFID Reader RC522

4. 1 buah AC/DC adaptor 12Volt 1Ampere

5. 1 buah single relay 5 Volt

6. 1 buah solenoid lock 5 Volt

\section{Jumper secukupnya}

A. Wiring

Pinout modul ESP32 terdapat pada Gambar 1.

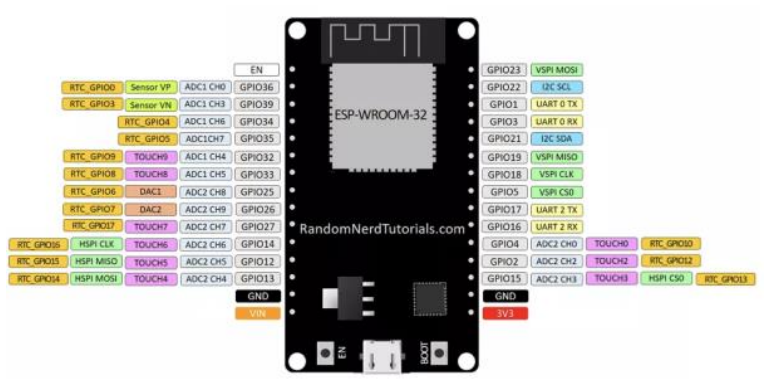

Gambar 1. Pinout ESP32

Dan pinout pada RFID reader RC522 bisa dilihat pada Gambar 2.

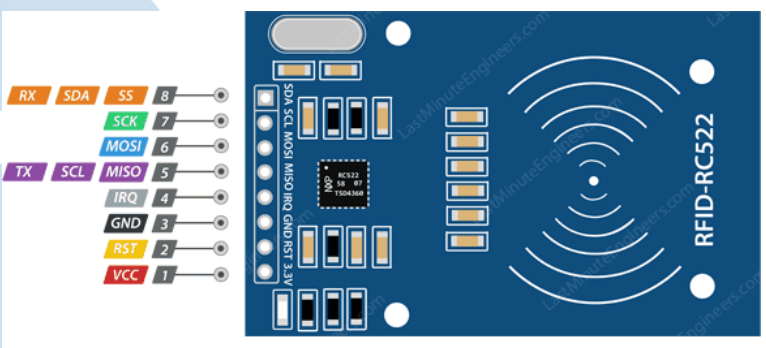

Gambar 2. Pinout RC522

Dan pinout dari single relay $5 \mathrm{~V}$ bisa dilihat pada Gambar 3.
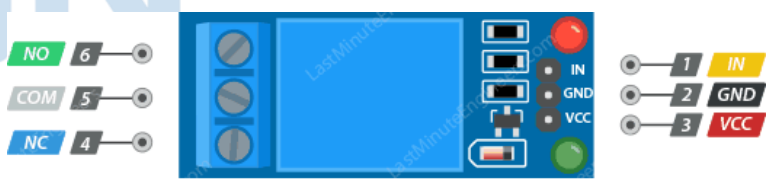

Gambar 3. Pinout single relay 5V

Dan wiring pada ketiga alat di atas akan ditunjukan pada Tabel 1 .

Tabel 1. Wiring table

\begin{tabular}{|l|l|l|}
\hline \multicolumn{1}{|c|}{ ESP32 } & \multicolumn{1}{|c|}{ RC522 } & \multicolumn{1}{c|}{ Single Relay 5v } \\
\hline $3.3 \mathrm{v}$ & $3.3 \mathrm{v}$ & - \\
\hline GPIO 22 & RST & - \\
\hline GND & GND & - \\
\hline- & IRQ & - \\
\hline GPIO 19 & MISO & - \\
\hline GPIO 23 & MOSI & - \\
\hline
\end{tabular}




\begin{tabular}{|l|l|l|}
\hline GPIO 18 & SCK & - \\
\hline GPIO 21 & SDA & - \\
\hline $3.3 \mathrm{v}$ & - & VCC \\
\hline GND & - & GND \\
\hline GPIO 13 & - & IN \\
\hline
\end{tabular}

rentan diretas. Kartu RFID HF $13.56 \mathrm{MHz}$ yang digunakan dalam penelitian ini adalah kartu yang cocok dengan reader RC522 yang juga akan digunakan.
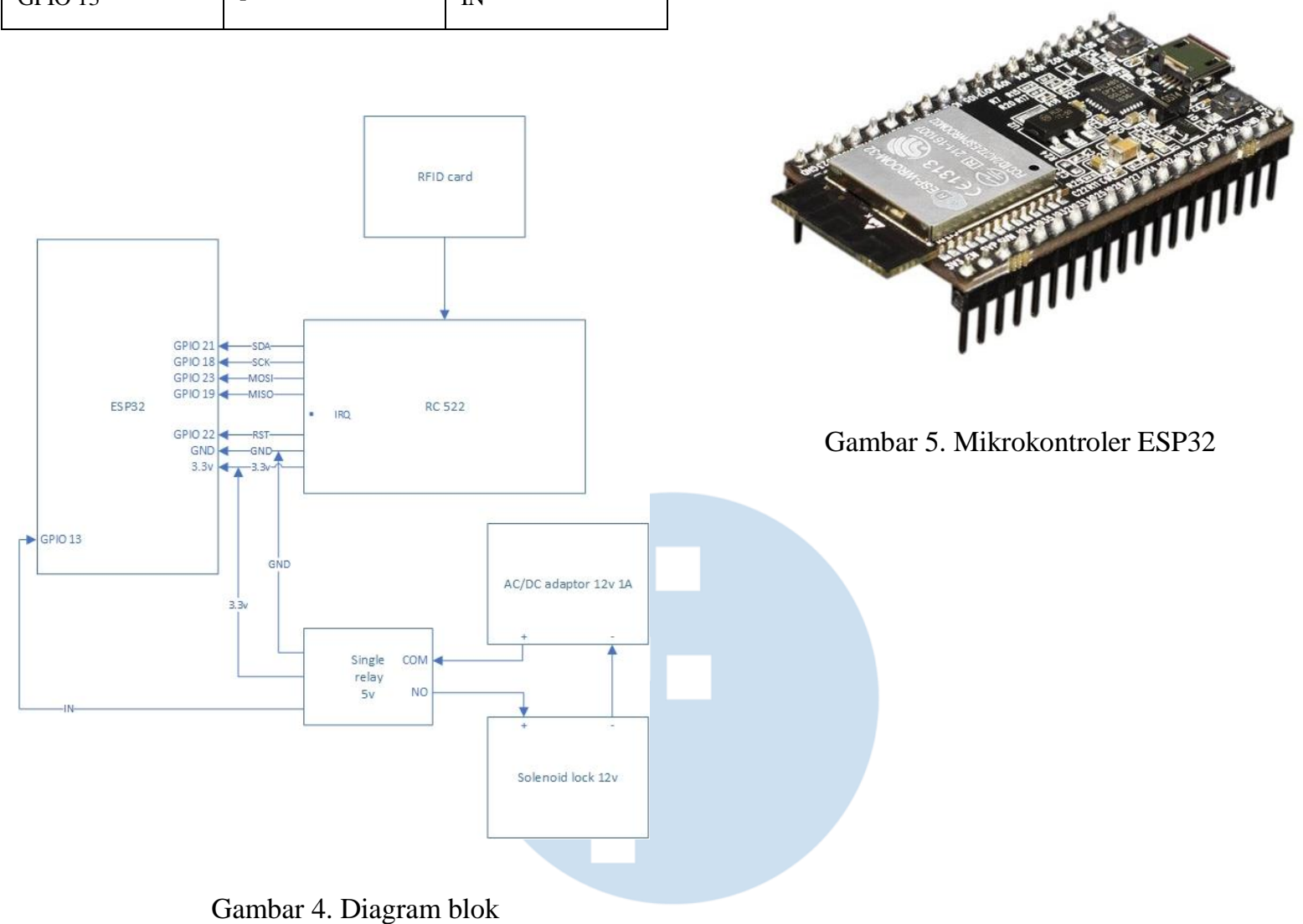

Gambar 5. Mikrokontroler ESP32

\section{B. Coding}

Ada beberapa coding dengan fungsinya masing - masing:

1. Passive Keyless Entry function

2. Digital Signature Algorithm

3. Locking \& Unlocking function

Fungsi program PKE adalah untuk memeriksa apakah terdapat tag/kartu RFID yang berada di se`r reader. Jika ada tag RFID terdeteksi, reader akan membaca UID yang dikirimkan oleh tag. Jika UID tersebut cocok saat dibandingkan dengan database maka akses pintu akan terbuka. Dari sistem yang terakhir adalah sistem buka tutup kunci yang berhubungan langsung dengan relay.

\section{IMPLEMENTASI DAN HASIL}

Pada implementasi penelitian ini, digunakan ESP32 dengan 30 pinout sebagai mikrokontroler dengan modul WiFi dan Bluetooth yang sudah terpasang. User identification (UID) dari setiap kartu RFID bawaan karena UID ini dianggap unik dan mudah untuk digunakan datanya walaupun sangat 


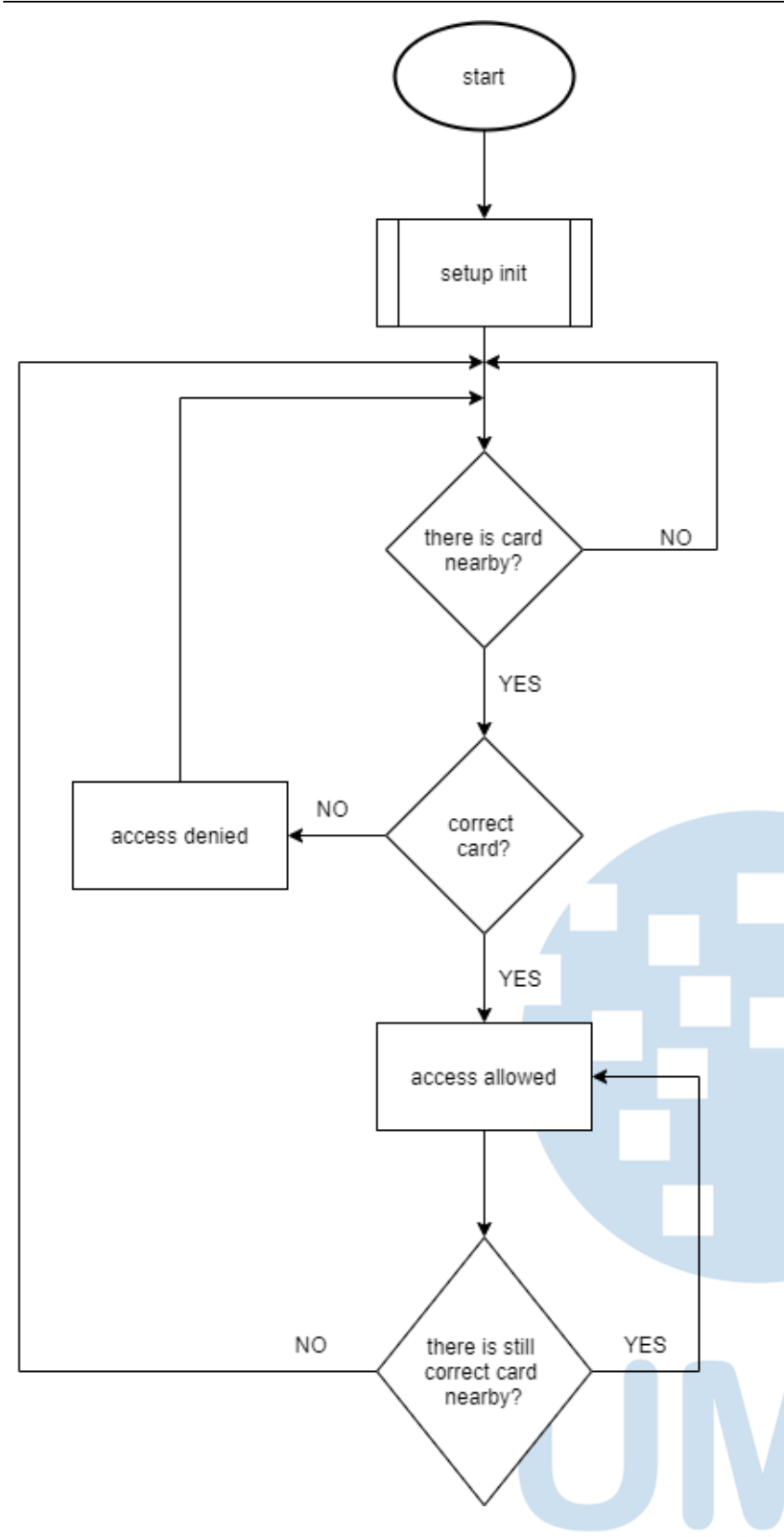

Gambar 6. Mikrokontroler ESP32

\section{A. Passive Keyless Entry}

Sistem PKE diimplementasikan dengan mengulang atau me-looping fungsi yang menahan kunci agar tetap terbuka ketika kartu RFID yang benar berada dekat dengan RFID Reader.

\section{B. Locking and Unlocking Function}

Fungsi ini hanya menggunakan pin yang dipasangkan dengan relay dan ketika HIGH maka kunci akan tertutup dan sebaliknya.

Sistem ini diujikan dengan menerapkan PKE menggunakan RFID dan ESP32 cukup berhasil karena fungsionalitas dari program dan alat yang buat berhasil dengan baik dengan jarak jangkauan dari RFID reader sekitar $5 \mathrm{~cm}$ dan ketika kartu RFID mendekati jarak tersebut, sistem akan merespons dengan 2 keadaan yang berbeda yaitu :

1. Ketika kartu yang benar maka kunci akan terbuka.

2. Ketika kartu yang salah maka kunci tetap tertutup dan memunculkan kalimat "access denied".

Namun masih banyak bug yang ditemui dalam implementasi walaupun secara fungsionalitas sudah tercapai. Bug yang paling sering terjadi adalah ketika kartu didekatkan RFID reader tetapi sistem tidak merespons sama sekali walaupun sudah dijauhkan dan didekatkan lagi. Solusi dari ini harus menekan tombol EN yang berada di ESP32 atau dengan me-restart sistem tersebut dan ada juga yang bisa ditambahkan pada program ini yaitu encryption dan decryption UID agar lebih aman dan hacker proof atau bisa juga dengan menambahkan hardware yang lebih bermutu dan lebih aman.

\section{SimPULAN}

Kesimpulan yang didapat dari percobaan ini adalah sistem PKE dihasil berfungsi dengan semestinya tetapi masih banyak bagian yang dapat dikembangkan agar sistem ini dapat digunakan dengan lebih mudah dan nyaman.

\section{UCAPAN TERIMA KASIH}

Terima kasih pada Bapak Dareen Kusuma Halim sebagai dosen sekaligus pembimbing dan Ibu Nabila Husna Shabrina karena telah memberikan bimbingan dalam penggunaan Radio Frequency.

\section{DAFTAR PUSTAKA}

[1] J. Jia, X. Cheng, and P. Wang, "Automobile Passive Keyless Entry Based ON RFID," DEStech Trans. Comput. Sci. Eng., no. International Conference on Computer, Electronics and Communication Engineering (CECE 2017), pp. 76-81, 2017, doi: 10.12783/dtcse/cece2017/14377.

[2] J. (Philips S. Becker, "Passive Keyless Entry and Drive Systems," Autotechnology, vol. 2, no. 6, pp. 56-58, 2002.

[3] M. B. Nugraha, P. R. Ardianto, and D. Darlis, "Design and implementation of RFID line-follower robot system with color detection capability using fuzzy logic," in ICCEREC 2015 . International Conference on Control, Electronics, Renewable Energy and Communications, 2015, doi: 10.1109/ICCEREC.2015.7337058

[4] Z. Zhi-yuan, R. He, and T. Jie, "A Method for Optimizing The Position of Passive UHF RFID Tags," in IEEE International Conference on RFID-Technology and Applications, 2010, no. June, pp. 92-95, [Online]. Available: 10.1109/RFIDTA.2010.5529867. 